\title{
A Quality Pathway to Digitalization in Manufacturing thru Zero Defect Manufacturing Practices
}

\author{
Ragnhild J. Eleftheriadis \\ SINTEF Raufoss Manufacturing AS (SRM) \\ Product and production Development \\ Trondheim, Norway \\ Ragnhild.Eleftheriad@sintef.no
}

\author{
Odd Myklebust \\ SINTEF Raufoss Manufacturing AS (SRM), \\ Vise president strategic projects \\ Trondheim, Norway \\ Odd.Myklebust@sintef.no
}

\begin{abstract}
Manufacturing industry has often used different types of quality improvements to reach a "near zero" perfection in product and process development this is often strategic objectives. Manufacturing of products with a large number of components and difficult geometries, often have high probability of detective output products.

Philosophies like Six Sigma, Lean i.e. are excellent to target these goals and make improvement in production development. Statistical tools and data collection are indicators that may improve the quality; however, a growing amount of data, "internet of things" (IoT) and Cyber Physical Systems (CPS) have led to complex manufacturing systems like Industry 4.0.

To document "Best Practices" it is necessary to understand the interoperability in an industrial setting. The author has harvested results from papers and a project, with focus on Zero Defect Manufacturing (ZDM). By structuring, the visual building blocks of Total Quality Management (TQM) both manual and automatically and together with a project guide made a ZDM Guideline for use in industrial settings.
\end{abstract}

Keywords-Best Practices, Zero Defect manufacturing, Industry 4.0, Chyber Physical Systems

\section{INTRODUCTION}

In many sectors like hospitals and air traffic control we can see very well implemented Best Practices (BP) for how to handle the flow of processes and quality issues in a safe way. Doctors and nurses have guidelines; pilots on airplanes have operational procedures to fulfil their work without hazard. It is important, due to the extent of damage on third party. Procedures and BP documentations is implemented and digitalized for walking through, step-by-step to ensure safety first.

In traditional industrial sectors and often SMEs, digital transformations are particularly lagging behind, this due to cost of implementation, skilled people and heavy investment in infrastructure. However, many industrial production sites in Europe have started strategic work towards a digital transformation in to the forth-industrial revolution named Industry 4.0 [1] [2]. Where use of big data, sensor and quality improvement of product and processes, goes as hand in glove. In the last five years, the digital economy has merged with the real economy and lead Europe into a data-driven economy says some of the commissioners in $E U$ [3]. The future factories of
Europe have made production priorities that include 3D printing, Cyber-Physical Systems (CPS), Internet of Things (IoT), robotics and customisation of innovative products. The strategic objectives for future manufacturing development are clearly identified by the Commission and communicated as important for the digitization of European Industry [3].

Quality assurance is one of the most important feedback loops for industrial improvements and a pathway to innovation and creation of new business models in an organization. The industry has several standards and well described documentations however Best Practices (BP) of how to implement this is not the same as the standards. Standards give only general recommendations and describes tick off lists, which is often difficult to implement due to customer specification.

In the fourth coming, integration of applications, or digitalized prescriptions and documentations will be implemented at the shop floor, this for best use and customization. To do this operation's and documentation specific BP documentation and knowledge sharing are need [4]. The human-to-human, machine-to-machine and machine-tohuman interaction is essential for managing and understand these process developments. Since the optimization of innovation processes can be described as "Best Practice" for implementation and operation in the whole value chain, for making the processes and production defect free [5] [6]. This paper will give some advice of important quality building blocks in digitalization, from a quality management perspective, and for further steps to inaugurate the new digital era of Industry 4.0.

\section{EVOLUTION IN QUALITY}

\section{The Quality toolbox for Continous Improvement (CI)}

Different definitions of Total Quality Management (TQM) is presented over the years, some claim "attempting to define TQM is like shooting at a moving target". Other argue that TQM as a corporate culture characterized by increased customer satisfaction through continuous improvement. In which all employees in the companies participate actively to fulfil. On the other hand, some claims that TQM is both a 
philosophy and a set of guiding principles for managing an organization [7]. TQM focuses on control of business processes and customer satisfaction. Activities such as improvement, statistical control, supply control and quality engineering are ingredients of TQM and TQM as a concept emanates from the academic field and has contributors such as Crosby, Juran and Deming [6] [5] [8].

Continuous Improvement (CI) is more generally a culture of sustained improvement targeting the elimination of waste in all systems and processes of an organization, named as Lean and Kaizen [9]. It involves everyone working together to make improvements without necessarily making huge capital investments. CI can occur through evolutionary improvement, in which case improvements are incremental, or though radical changes that take place because of an innovative idea or new technology. Often, major improvements take place over time as a result of numerous incremental improvements.

Henry Ford systemized mass production in manufacturing during the early nineteenth century. Japanese adopted lean manufacturing and improved it. This methodology is a systematic approach to identifying and eliminating waste through CI by following the product at the pull of the customer in pursuit of perfection. In the 1950s, the Toyota Motor Company first implemented Quality Circles within the production process itself, and today Toyota Production System (TPS) or Lean as is well known for reduce of waste in production management [10]. Kaplan and Norton started to use Balanced Scorecard and key performance indicators (KPI) to link achievements to business strategy [11]. Deming believed that traditional quality assurance methods, such as product inspection after manufacturing were inefficient at finding the source of variations, which often occurred throughout the production process. He pointed out that all business processes had to be considered and that they all needed feedback loops in order to improve [8].

In the late eighth Motorola started to use statistical process control (SPC) as a measuring of processes and implemented this as strategical methods for analysis of their own production. With implementation of Six Sigma as an approach and philosophy for more stable and optimized production, they managed to make dramatic reductions of costumer defined defected rates [12]. The reduction of variation in the processes was a matter of fact at a level close to "Zero". The concept of ZDM is building on this philosophy together with use of IoT and feedback loops. However, the Six Sigma approach has a different view of organization and customer relation compare to ZDM. Today we can see that organizations like GE, Honeywell, ABB and more have been using a Six Sigma approach to streamline their business excellence.

\section{Zero Defect Manufacturing}

Zero Defect (ZD) is not a new concept either philosophy, the US Stat Secretary of Defense used the term as early as 1965 and they implemented this as a quality and reliability program [13]. The most important for implementing ZD was what it not was meant to be;

- not a speed up program
- not an employee evaluation technique

- either a substitute for quality control

- or a technique for ensuring error

It was an approach for elimination of defects attributable to human error, to inspire personnel at all levels in the organization to do their jobs right at the first time. The ZD concept recognize that event though a person is dedicated, well trained and use many tools they do not necessarily do defect free work. It needed something more like a reminder that his contribution to the quality of a product is important and recognized by the management. The Department of Defense highlighted strong commitment and directions for achieving success such a program, with reference to the President of the US [13].

$\mathrm{ZD}$ in production development needs attention in each process stage. This is a necessity since no one will make defects faster and more rapidly and for finished product with high cost and heavy workload it is crucial to do the work right at first attempt as Crosby refer to in his book "Quality is free", but he also pointed out that to do this right is not necessary cheap. Today the quality concept of $\mathrm{ZD}$ is one of the befit for implementing Industry 4.0 in manufacturing processes and the digitalization of manufacturing. Cyber Physical System (CPS) is the philosophy behind such a concept, the steps is easy, if you do the right quality implementations first with the right building blocks it is possible to digitalize whole you production site. The next step into a digital world is open, however you need to know in which process and at which stage you start the improvement for further digitalization and optimization [14] [15] [16].

\section{Cyber Physical Systems (CPS)}

CPS or CPPS (Cyber Physical Production Systems) is the new approach within digitalized manufacturing development and by reaching the next generation of the digital development, you can full field the main goals of "Zero Defect Manufacturing". CPS and CPPS is the description of the physical assets connected to the virtual worlds. The methodology will create a new framework for state of the art production systems, with integrated CPS and IoT technology. The approach will open to the opportunity of developing improved self-learning equipment, with novel software and hardware, which will allow their output optimization [14] [16].

Cyber-Physical Systems (CPS) is embedded computers and networks that monitor and control the physical processes, usually with feedback loops where physical processes affect computations and vice versa. The economic and societal potential of such systems is vastly greater than what been realized, and major investments are being made worldwide to develop the technology. CPS will play a key role in this opportunity of re-industrialization of EU, especially considering that EU has $30 \%$ of the world production of embedded systems in high added value sectors such as automotive, aerospace and healthcare [1]. These technologies are leading to the creation of smart and virtual factories, as well 
as enhancing both the vertical and horizontal integration of the industry 4.0 vale chain as shown in Figure 1.
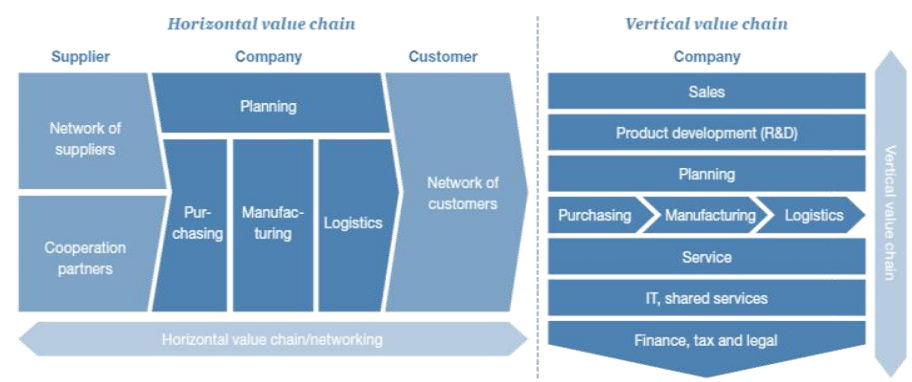

Fig. 1. Horizontal and Vertical Value Chain in Industry 4.0 [2]

In the last years, CPS have been adopted in aerospace, electric, transportation, healthcare, and housing industries to support both vertical and horizontal integration of ICT systems. However, since CPS are implemented in heterogeneous environments, companies need new architectures able to seamlessly integrate several heterogeneous automation software conceived in diverse domains (e.g. control, diagnostic, modelling, process rendering, human machine interfaces, etc.) of the factories [14] [16] [15].

\section{QUALITY STEPS INTO THE "EMERGENT TECHNOLOGIES" AND PRODUCTION LIFECYCLE MANAGEMENT (PLM)}

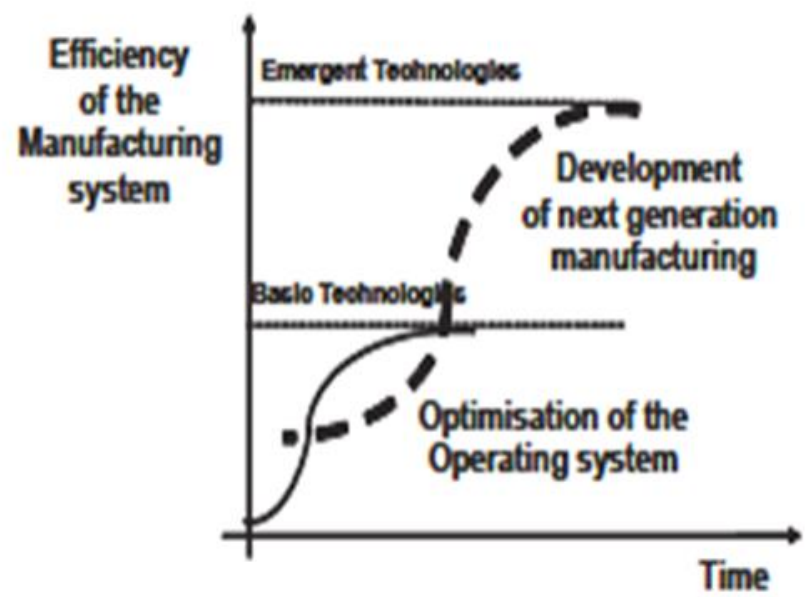

Fig. 2. Time scale of strategic manufacturing development or innovation steps in manufacturing [17]

With references to Figure 2, Professor Westkämper at University in Stuttgart, publicized the elements of innovative technologies as "Emergent Technologies" [17] and he highlighted the complex integration of ZDM as a possible enabler for Industry 4.0 [18]. The background is that the basic process technologies in mechanical engineering is a need for managing the next step in an innovation process.

Adaptive and functional materials offers many new applications. Measurement, forming and geometric complexity, which in usual manufacturing would have been series production. In the future development, this will be on $3 \mathrm{D}$ printer systems or additive manufacturing; He mentioned the digital technologies in manufacturing as effective engineering in smart factories.

To scale the strategical development he uses a model for lifecycle technologies, where the core areas are;

- product

- process

- organisation

the time scale of basic research implementation. Known as the innovation steps in to a more optimized production.

Short time scale is set by turbulent environment and will be optimized by adding value and customizing the operating system. In this area, Lean Management and Toyota Production System (TPS) methodologies are well known. Long-term implementation needs a broad strategical orientation of the marked and investments in knowledge and IT infrastructure, named as "Emergent Technologies" or today we know that ZDM and CPS is basis of statistical process control and ICT driven systems that can provide predictability and reliable automated systems for the manufacturing system. Thru this scale of manufacturing development, we can add all the typical quality systems, for a more detailed overview.

The quality building block in a digital framework by use of Zero Defect Manufacturing

To buy stat-of-the-art engineering technology is easy, and can be implement fast with a lot of tools. However, to build a culture for improvement and implement best practices is hard work. The awareness of customer feedback is essential for change of mind-set in organizations, their skills and capability is what bring their business solutions further to innovative solutions. Those companies that develop strategic and sustainable culture will have most success since this is difficult to copy and buy [7].

From a Product Lifecycle Management (PLM) perspective, it is hard to reach the key enabling technologies in a new development such as Industry 4.0 due to the importance of having the right building blocks implemented in the company's philosophy and culture. On the other side, to move to the next innovation path there is a need for some guidelines and stepwise advises in the quality era to reach the full potential for going from manual to ICT powered digitalization. 


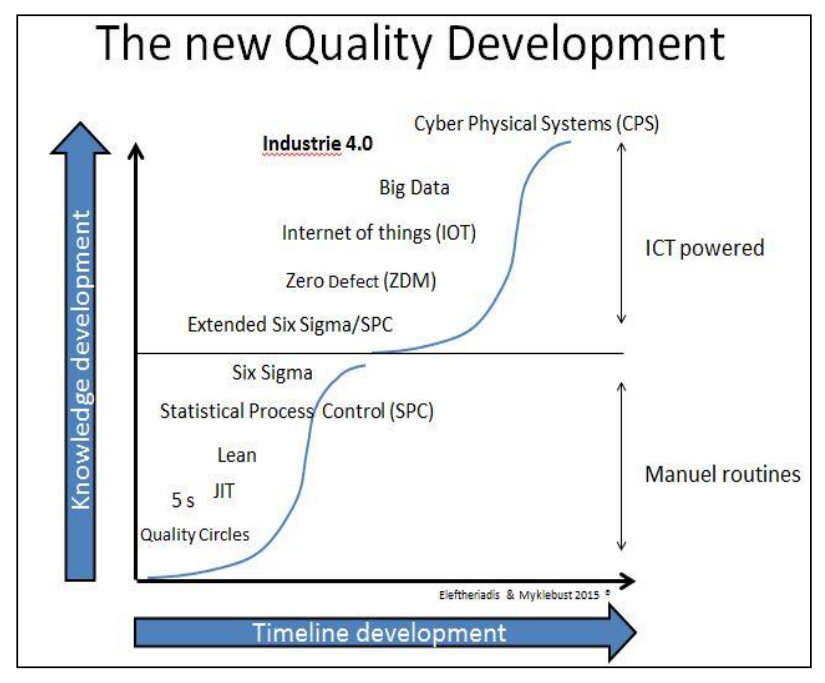

Fig. 3. Visualization of the innovation perspective of the quality building blocks for digitalization [4]

To climb on the innovation s-curve you need to have some quality building blocks as shown in Figure 3 the climbing scurve describe the most common quality tools for implementation of ZDM and Industry 4.0 in production development.

\section{A stepvise guideline to Zero Defect Manufacturing}

Thru several reviewed papers into the area of project management and quality performance, the author have find that there are some certain similar steps but also some differences, if you compare manual quality performance and digital quality performance.

Table 1. provide the most natural steps of how to implement Zero Defect Manufacturing as a Guideline for Best Practices and as a project management procedure in an industrial setting.

TABLE I. GENERIC GUIDELINE FOR ZERO DEFECT MANUFACTURING

\begin{tabular}{|c|c|c|}
\hline \multirow[t]{2}{*}{ Step } & \multicolumn{2}{|c|}{$\begin{array}{l}\text { Generic Guideline for Zero Defect Manufacturing (ZDM) } \\
\text { Project Procedure }\end{array}$} \\
\hline & Description of Procedures & Important achievements \\
\hline 1. & $\begin{array}{l}\text { Define areas or functional } \\
\text { units for ZDM and define } \\
\text { the problem (What should } \\
\text { really be improvement) }\end{array}$ & $\begin{array}{l}\text { - Strategic goals, in the } \\
\text { organisation } \\
\text { - Split down processes }\end{array}$ \\
\hline 2. & $\begin{array}{l}\text { Define what the final goals } \\
\text { are or how the improved } \\
\text { quality level }\end{array}$ & $\begin{array}{l}\text { - Critical to quality } \\
\text { parameters } \\
\text { - Risk Analysis } \\
\text { - Scrap rate in percent } \\
\text { - Cost, material and rework } \\
\text { reduction } \\
\text { - Effectiveness }\end{array}$ \\
\hline 3. & $\begin{array}{l}\text { Define project teams with } \\
\text { responsible and skilled } \\
\text { project manager }\end{array}$ & $\begin{array}{l}\text { - Leadership, Process task } \\
\text { responsible } \\
\text { - Cross disciplinary teams } \\
\text { - Culture and vision for ZDM }\end{array}$ \\
\hline 4. & $\begin{array}{l}\text { Describe "As Is" situation } \\
\text { Describe "To Be" situation }\end{array}$ & $\begin{array}{l}\text { - Use a conceptual model i.e. } \\
\text { IDEF } 0 \text { or CIMMI } \\
\text { - Describe in detail by using } \\
\text { IDEF } 0 \text { the real situation }\end{array}$ \\
\hline
\end{tabular}

\begin{tabular}{|c|c|c|}
\hline \multirow{2}{*}{ Step } & \multicolumn{2}{|c|}{$\begin{array}{l}\text { Generic Guideline for Zero Defect Manufacturing (ZDM) } \\
\text { Project Procedure }\end{array}$} \\
\hline & Description of Procedures & Important achievements \\
\hline & & $\begin{array}{l}\text { Describe the future } \\
\text { perspectives }\end{array}$ \\
\hline 5. & $\begin{array}{l}\text { Determine nature or } \\
\text { improvement solutions }\end{array}$ & $\begin{array}{l}\text { - Human aspects } \\
\text { - Risks and migration } \\
\text { - Hardware solutions } \\
\text { - Software and tailor made } \\
\text { solutions }\end{array}$ \\
\hline 6. & $\begin{array}{l}\text { Determine critical and } \\
\text { hidden parameters and } \\
\text { functions to be improved }\end{array}$ & $\begin{array}{l}\text { - Change use of work methods } \\
\text { - Online sensor and measuring } \\
\text { - Machine \& equipment tools } \\
\text { (test-improve) } \\
\text { - Test and failure in } \\
\text { improvement work } \\
\text { - Modify control of software } \\
\text { systems }\end{array}$ \\
\hline 7. & $\begin{array}{l}\text { Development testing } \\
\text { Implementation } \\
\text { Validation } \\
\text { Pilot operation }\end{array}$ & $\begin{array}{l}\text { - Test and measure in real } \\
\text { environment } \\
\text { - Make implementation plans, } \\
\text { Risk Matrix and } \\
\text { Contingency plans } \\
\text { - Control and collect and then } \\
\text { re-test } \\
\text { - Improvement on pilots, } \\
\text { Patent }\end{array}$ \\
\hline 8 & $\begin{array}{l}\text { Evaluation } \\
\text { New measurement and } \\
\text { potential new loop }\end{array}$ & $\begin{array}{l}\text { - Ask for external feedback } \\
\text { - Go back to step } 1 \text {. for new } \\
\text { Goals or process } \\
\text { improvements }\end{array}$ \\
\hline
\end{tabular}

The author made a step-by-step guideline reflecting a project baseline description and this will for many companies and special small factories have a description of how to start the first step to recognize their own capability [4]. This guideline will show the most common quality steps, by making a matrix for selection and choosing the right tool for the next step for own organization.

Then it is possible to go further to find vital process parameters and tolerances that is essential for knowing your own product, process and the KPI goals for your product. The last is to select sensors and use some useful guides that tell you in detail what you are looking for. Where to place, how to use and where to buy the equipment, this is pure engineering and easy to buy today. All this processes is interoperable processes, in which be used over the lifecycle and could be integrated with common quality tool, statistical and digital systems like CyberPhysical Systems [4] [15].

\section{CONCLUSION AND FUTHER WORK}

The quality approaches such as Lean, TQM, Six Sigma, and ISO standards outline a desired end state and demand for selfthinking by the organization and can be very useful if handled carefully. Six-sigma is a result of a continuous quality consciousness in the business world; it is a more logical and pragmatic approach than many of the other TQM approaches; however, Six-sigma is more mathematical and rigorous in its approach. 
Zero Defect as a quality approach can be used as a combination of TQM, Six Sigma and Lean together with IoT and other digital or artificial intelligent systems. The output will give increased predictability not only in the machine, but also right use of data and signals, that allows you to monitor time cycle, deviations and localize defects an early stage. In addition, handling of acquisition and use of "Big Data" can pave the way for new technologies as we today find in Cyber Physical Systems.

\section{REFERENCES}

[1] Eurostat, "European Commision, Eurostat Pocketbook, High-tech Statitics," European Commission, Luxembourg, 2013.

[2] A. Demmer, "Industrie 4.0 The Aachen Approach, Franunhofer Institute for Production Technology IPT," WZL Aachen, Fraunfhofer IPT, Oslo, 2015.

[3] B. p. f. E. Commission, "Digitising European Industry," European Commission, DG Connect, Components and Systems, Brussels, 2015.

[4] R. Eleftheriadis, "ZDM Guideline Process Flow Map based on IFaCOM," NTNU, Trondheim, 2015.

[5] J. M. Juran, Quality Control Handbook, Third ed., New York: McGraw Hill, p5-12, 1979.

[6] P. Crosby, Quality is Free, New York: McGraw-Hill, 1969.

[7] K. Linderman, R. G. Schroeder, S. Zaheer and A. S. Choo, "Six Sigma: a goal-theoretic perspective," Journal of Operational Management 21(2003), vol. 21, no. 2003, pp. 193-203, 2003.

[8] E. Deming, "Out of the Crisis", Quality, Productivity and Competitive Position, Cambridge, Massacuet: MIT Press, 1982.

[9] N. e. A. Slack, Operations Management, Sixth Edition, Essex, England: Pearson Education Limited, 2010.

[10] J. P. Womack, D. T. Jones and D. Roos, The machine that changed the world, New York: Rawson Associated Scribner, 1990.

[11] R. S. Kaplan, and D. P. Norton, Translating Strategy into action, The Balanced Score Card., Boston, Massachusetts: Harvard Business School Press, 1996.

[12] J. Antony, R. Banuelas and A. Kumar, World Class applications of Six Sigma, Real Wold Expamples of success, 1 st edition ed., Oxford: Elsivier, Butterworth Heinemann, 2006.

[13] G. Foche, "A guide to Zero Defects, Quality and Reliability Assurance Handbook," Offiice of the assistant secretary of defence, US. , Washington, 1965.

[14] E. A. Lee, "Chyber Physical System; Design Challenges," Universtiy of California at Berkeley, Technical Report No. UCB/EECS-2008-8, San Fransico, 2008.

[15] L. Monostori, "Chyber-Pysical production systems: Roots, expectations and R\&D challenges," in Proceedings of the 47th CIRP Conference on Manufacturing, Elsivier, Canada, 2014.

[16] J. Lee, B. Bagheri and H.-A. Kao, "A Cyber-Physical Systems architecture for Industry 4.0 based manufacturing systems," Sience Direct, Manufacturing Letter, Vols. -, no. 3, pp. 18-23, 2015.

[17] E. Westkämper, "Strategic Development of Factories under the Influence of Emerget Technologies," CIRP Annals, vol. 56, no. doi:10.1016/j.cirp.2007.05.100, pp. 419-422, 2007.

[18] E. Westkämper and H. J. Warnecke, "Zero-Defect Manufacturing by Means of a Learning Supervision of Process Chains," Elsevier, CIRP Annals - Manufacturing Technology, vol. 43, no. 1, pp. 405-408, 1994. 